\title{
Sipple syndrome: marked variability of the disease within a family and implications for management
}

\author{
*John C. Stevenson \\ M.B., M.R.C.P.(U.K.) \\ *Evangelos Spanos \\ M.D., M.Sc., Ph.D. \\ $\dagger$ Nigel ACKROYD \\ M.R.C.P.(U.K.)., F.R.C.S. \\ $\ddagger$ MORRIS J. BROWN \\ B.A., M.R.C.P.(U.K.)
}

*CARmel J. Hillyard

B.Sc., Ph.D.

*IAin Macintyre

D.Sc., F.R.C.P., F.R.C.Path.

$\dagger$ JOHN LYNN

M.S., F.R.C.S.

BonNiE M. STEVENSON

S.R.N., N.D.N.Cert.

The * Endocrine Unit, the Departments of $\uparrow$ Surgery and $\ddagger$ Clinical Pharmacology, Royal Postgraduate Medical School, Hammersmith Hospital, Du Cane Road, W12 OHS

\section{Summary}

Familial medullary carcinoma of the thyroid gland is often associated with phaeochromocytoma; this condition is known as Sipple syndrome. The rate of progression of the disease and the degree of malignancy of the medullary carcinoma may vary from family to family. Thus the nature and behaviour of this disease in any particular family influences the management of the thyroid carcinoma component. The authors measured plasma calcitonin and plasma catecholamines in $\mathbf{2 1}$ members of a family with Sipple syndrome. In one branch of this family 5 out of 7 members have so far been affected, 4 with metastases or recurrence of the carcinoma and 2 with development of phaeochromocytomas. In contrast, of the $14 \mathrm{mem}$ bers in the other 4 family branches, only 4 have had pathologically elevated plasma calcitonin concentrations following alcohol provocation, probably representing C-cell hyperplasia or very early neoplasia and apparently not progressing. None has evidence of phaeochromocytoma.

This family demonstrates a striking variability in the natural history of Sipple syndrome which, despite increasing discovery of more families with medullary thyroid carcinoma, has not been previously reported. In the light of this finding, a reappraisal of the management of the thyroidal component of this

Requests for reprints: Dr John C. Stevenson. disease is necessary. It appears that radical nec $\vec{k}$ surgery may be needed to prevent recurrence of the disease.

\section{Introduction}

Medullary carcinoma of the thyroid gland was first described in 1959 (Hazard, Hawk and Crile, 1959). It arises from the parafollicular cells of the thyroid gland (Williams, 1966). These cells, now known as C-cells (Pearse, 1966), are derived from the neural crest and secrete the peptide hormone, calcitonin (Foster, MacIntyre and Pearse, 1964). Thus medullary thyroid carcinomas are usually associated with raised circulating concentrations of calcitonin (Cunliffe et al., 1968; Hillyard et al., 1975). The occurrence of the tumour may be sporadic or familial, the latter often being associated with phaeochromocytoma (Sipple, 1961) when it is known as Sipple syndrome. In this familial form, which has an autosomal dominant inheritance (Schimke and Hartmann, 1965), calcitonin concentrations tend to be lower than in sporadic cases, and a small but significant number of patients have basal concentrations that are within the physiological range (Deftos, 1974). These patients represent the earliest stages of the disease, having only hyperplasia or early neoplasia of the C-cells. Provocative tests are therefore used to detect the disease in its 
early stages and all members of an affected family must undergo such tests. There is no indication to perform stimulatory tests in subjects with elevated basal calcitonin concentrations. The standard treatment for a familial medullary thyroid carcinoma is total thyroidectomy as the tumour is invariably bilateral (Wells et al., 1975; Taylor, 1977). Both radiotherapy and chemotherapy are ineffective in this condition.

Unfortunately, provocative testing will not indicate those subjects with completely normal thyroid glands who will go on to develop the disease, as is illustrated by the authors' continuing studies on a family with Sipple syndrome. Furthermore, management of such patients becomes complicated by the fact that the disease appears capable of running completely different courses even within the same family. The authors performed serial measurements of plasma calcitonin after provocative tests in 21 members of a family with Sipple syndrome. Plasma catecholamines were also measured to screen for phaeochromocytoma. The advantage of plasma catecholamine measurements over urinary VMA estimations is that the former give accurate and reproducible results (Bravo et al., 1979), especially on an out-patient basis whereas unsupervised urine collections are frequently unreliable.

\section{Patients and methods}

Twenty-one members of a family were studied. Alcohol tests (Dymling et al., 1976) were performed on all members, this being the authors' provocative test of choice for screening for medullary thyroid carcinoma (Stevenson and Hillyard, 1980). Venous blood was taken with appropriate timing into cooled heparinized tubes and centrifuged immediately. The plasma was at once separated and frozen. All plasma samples were stored at $-20^{\circ} \mathrm{C}$ until assay for either calcitonin or noradrenaline and adrenaline.

In the original screenings, plasma immunoreactive calcitonin was measured by a radioimmunoassay technique (Clark et al., 1969). From 1979 onwards, it was measured by that radioimmunoassay modified by using antisera raised in rabbits against synthetic human calcitonin which give a sensitivity for the assay of approximately $2 \mathrm{pg}$ per tube under optimal conditions using a 7-day incubation. The 2 antisera used were both well characterized using fragments of synthetic human calcitonin. They had similar immunochemical and immunological characteristics, both binding to 2 parts of the calcitonin molecule: the major site was between amino-acids 11-28, with a minor site at the $\mathrm{C}$ terminal.

Quality control samples assayed with the second antiserum gave results within 2 standard deviations of the mean (calculated when 10 samples of each control plasma were assayed in a single assay using the first antiserum). Intra- and interassay variations were $<8 \%$ and $<10 \%$ respectively. Physiological calcitonin values are usually below $120 \mathrm{ng} / \mathrm{l}$.

Plasma noradrenaline and adrenaline were measured by a radioenzymatic technique (Da Strada and Zunchtes, 1976). Intra- and interassay variations were $3.7 \%$ and $5.8 \%$ respectively.

\section{Results (Fig. 1)}

The original tests showed 4 subjects $(1,6,7$ and 9) with elevated basal calcitonin concentrations who were all in the same branch of the family (A) (Table 1). They all underwent total thyroidectomy, and medullary carcinoma was found in each case. Postoperatively, calcitonin concentrations becams undetectable in the 3 males $(1,6,9)$ but those in the female (7) remained elevated. They have risen progressively from $3.25 \times 10^{3} \mathrm{ng} / \mathrm{l}$ to the present level of $156.0 \times 10^{3} \mathrm{ng} / \mathrm{l}$. Hepatic metastases have now been demonstrated in this patient. The calcitonin concentrations in one of her siblings (6) have remained completely undetectable but at subsequent screenings, her father (1) and youngest brother (9) were found to have detectable circulating calcitonin again; this represents a recurrence of the medullary carcinoma 3 and 4 years respectively after thyroid surgery. Another sibling (8) with previously normal plasma calcitonin concentrations was found to have high basal and provoked concentrations at a screening in May 1979. She immediately underwent a total thyroidectomy and a locally-invading thyroid medullary carcinoma was removed. Unfortunately, plasma calcitonin concentrations have remained elevated, probably representing metastatic neoplasia.

Raised plasma adrenaline concentrations with normal plasma noradrenaline were found in subjects 1 and 7. In both cases, 24-hr urinary VMA estimations were normal. Bilateral phaeochromocytomas were found at operation in case 1 , and unilateral in case 7 . These were all successfully removed.

In the other branches of the family (B-E), 3 members $(4,12,15)$ originally had slightly elevated calcitonin concentrations on provocation. These have not increased over a period of 2 years. A further subject (17) now has slightly elevated concentrations of circulating calcitonin with provocative testing. None has an elevated basal calcitonin and plasma catecholamine concentrations are within normal limits.

With the exception of subject 7 , all members of the family have been free of any symptoms. Serum calcium concentrations are normal in all members and it has not as yet been necessary to measure plasma PTH in this family.

The first and second generations of each branch of this family are of a fairly comparable age. 


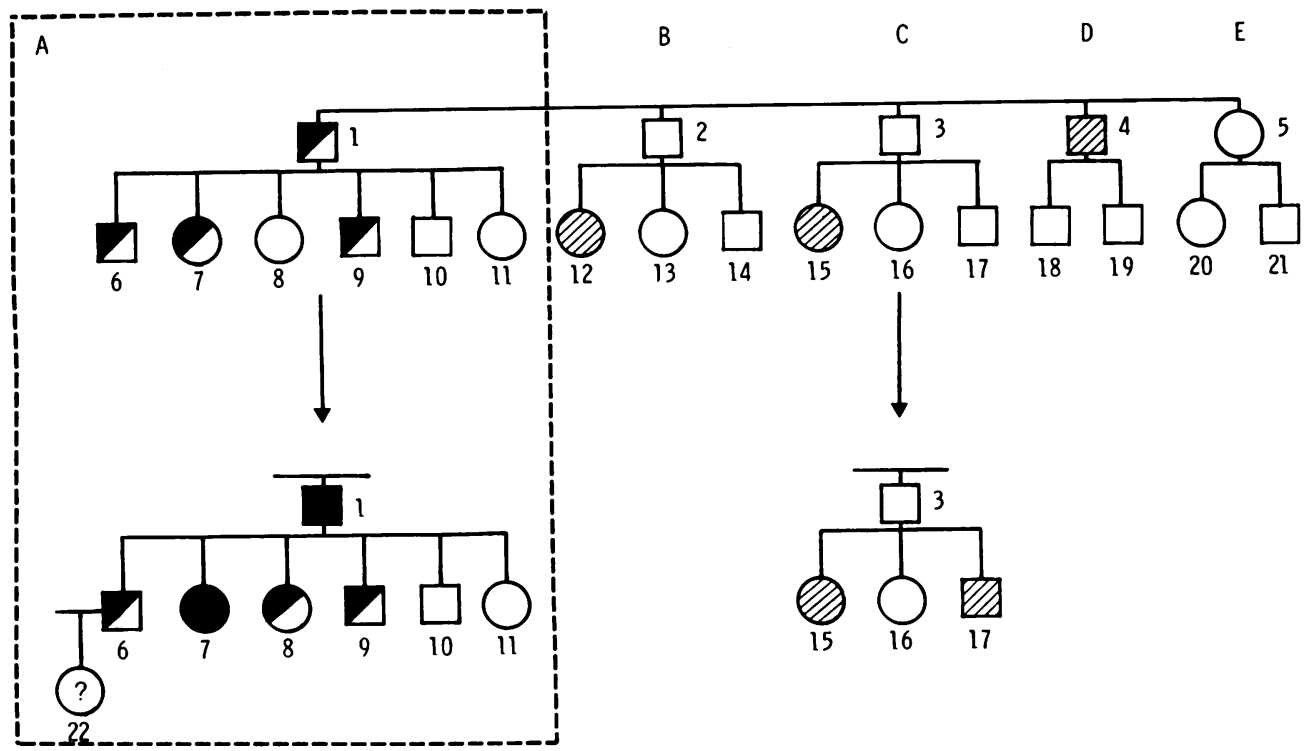

FIG. 1. Family tree showing affected members and progression of their disease over a 4-year period. $\square$, Medullary thyroid carcinoma + phaeochromocytoma; $\boldsymbol{Z}$, medullary thyroid carcinoma; $\mathbb{Z}$, hypercalcitoninaemia following provocation; (?), not tested.

TABLE 1. Plasma calcitonin concentrations (ng/l) taken at presentation, following total thyroidectomy (when performed) at subsequent screenings in all members of family branch $\mathbf{A}$

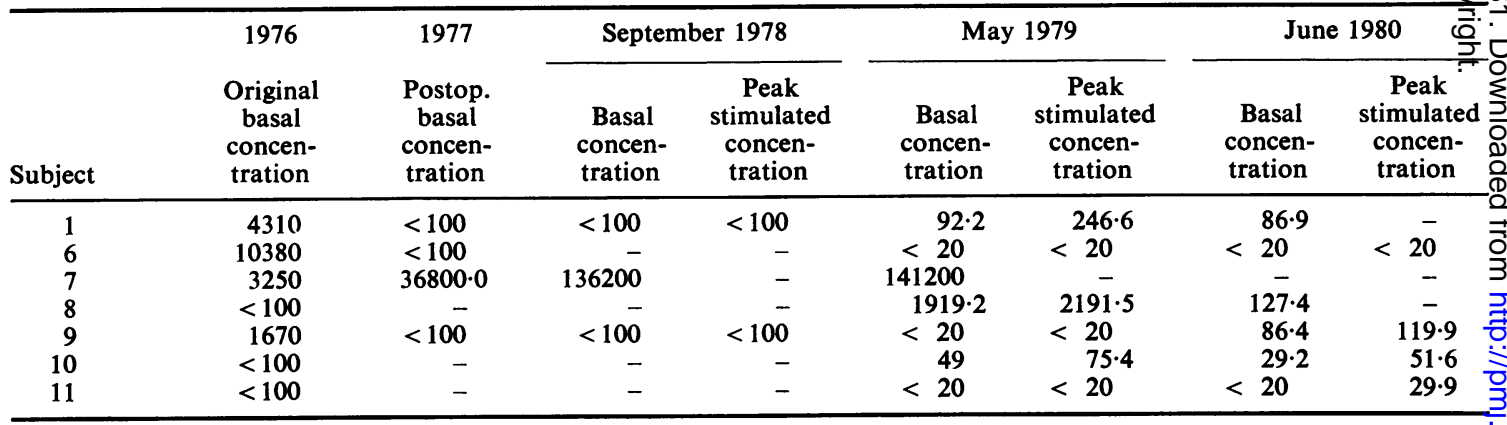

\section{Discussion}

This family suffers from Sipple syndrome, also known as multiple endocrine adenomatosis (MEA) type IIa. Besides medullary carcinoma and phaeochromocytoma, there is an increased incidence of parathyroid disease in this condition (Sarosi and Doe, 1968; Steiner, Goodman and Powers, 1968). This is in contrast to MEA type IIb where there is an association with mucosal neuromas (Block et al., 1975).

The course of the disease is variable. In some families it is an aggressive condition with a highly malignant thyroid carcinoma, whilst in others the disease may run a benign course and be compatible with a normal life span (Ljungberg, 1972). This variability is extremely important in the manage- ment of the disease. Obviously, if a phaeochromo cytoma is demonstrated it is always removed as aO priority. But with regard to the medullary thyroid carcinoma, surgical intervention may not be neces-음 sary in every case. The decision as to whether or not $>$ to proceed with thyroid surgery is usually based on․ㅡ. the historical nature of the disease in that particularn family (Editorial, 1977). Thus, an asymptomatic ${ }^{-}$ patient with mild hypercalcitoninaemia belonging to 0 a family in which medullary thyroid carcinoma has been found to be compatible with a normal life would usually be treated conservatively with inter mittent monitoring of calcitonin. However, in this family under study, the disease seems to be running.? 2 separate and entirely different courses.

In one branch of the family, the disease appears to $\stackrel{\vec{D}}{\vec{D}}$ 
be highly aggressive. Five out of 7 members have developed medullary thyroid carcinoma, 4 with recurrence or residual disease following surgery. In addition, 2 subjects $(1,7)$ have developed phaeochromocytomas. And one subject (8) who previously had no evidence of any thyroid disease as shown by normal plasma calcitonin concentrations with provocative testing has progressed through the stage of C-cell hyperplasia to invading and metastatic neoplasia within 3 years.

In complete contrast, the disease in the other branches of the family appears to be running a fairly benign course. Only 4 members out of 14 have been shown to have mildly elevated calcitonin concentrations with provocative testing. These concentrations have not increased in any of the subjects $(4$, $12,15,17)$ and it is likely that these concentrations represent hyperplasia of the thyroidal C-cells, or early neoplasia which is not progressing. None of these subjects has any evidence of phaeochromocytoma.

Thus, the management of this family comprises 2 differing approaches. The branch of the family with rapidly progressive disease (branch $A$ ) requires frequent screening of circulating catecholamine concentrations in order to detect both occurrence and recurrence of phaeochromocytoma. Any such event would prompt immediate surgical intervention.

With regard to the medullary thyroid carcinoma, the 2 unaffected members of the family will be screened regularly. If calcitonin concentrations above $200 \mathrm{ng} / 1$ are detected either before or after provocation, this will be regarded as indicative of actual or impending neoplasia. It is obviously important that surgical intervention in the disease be undertaken as early as possible in view of the rapid progression in affected members. Furthermore, it appears that total thyroidectomy alone may be insufficient as late recurrence of the disease has occurred in 2 patients. Since C-cells may occur in both the parathyroids and the thymus (Galante $e t$ $a l ., 1968)$ and they may also undergo neoplasia, the authors recommend a more radical surgical procedure. Total thyroidectomy should be accompanied by total parathyroidectomy and extensive removal of thymus and local lymph glands. Parathyroid tissue should be reimplanted in the forearm to prevent permanent hypoparathyroidism.

In the rest of the family (branches B-E) there is no evidence that the disease is running an aggressive course. Indeed, there has now been no evidence of progression of the disease in the 4 affected members for over 4 years. They will continue to be screened intermittently for phaeochromocytoma and medullary carcinoma. Thyroid surgery will only be performed if calcitonin concentrations become suspicious of frank neoplasia (basal or stimulated concentrations $>1000 \mathrm{ng} / \mathrm{l})$.
Future management of all cases of Sipple syndrome will require regular and often frequent estimations of plasma calcitonin and catecholamines. This necessitates the availability of suitable assay techniques. Therefore, any cases of familiar medullary thyroid carcinoma should probably be managed by endocrinological surgeons and physicians in specialized centres with these facilities.

A rapidly changing or progressive course, if shown by increasing serial plasma calcitonin levels, warrants surgical intervention even in a family with disease of an historically-demonstrated benign nature. It appears that radical neck surgery will be necessary in order to prevent recurrence of familial medullary thyroid carcinoma.

Continuing studies of this family with Sipple syndrome have revealed strikingly different courses of the disease within the family. The possibility of such a variation of the disease within any particular family group must be borne in mind by the clinicians with care of families with medullary thyroid carcinoma or Sipple syndrome of an apparently benign nature.

\section{Acknowledgments}

We thank Dr J. Mackett for his help and provision of facilities. We also thank Dr Imogen Evans for her helpful comments on the manuscript. This work was supported in part by the Arthritis and Rheumatism Council and the Cancer Research Campaign.

\section{References}

Block, M.B., Roberts, J.P., Kadair, R.F., Seyfer, A.E., Hull, S.F. \& NofeldT, F.D. (1975) Multiple endocrine adenomatosis type IIb. Journal of the American Medical Association, 234, 710.

Bravo, E.L., Tarazi, R.C., Gifford, R.W. \& Stewart, B.H. (1979) Circulating and urinary catecholamines in pheochromocytoma. New England Journal of Medicine, 301,682 .

Clark, M.B., Boyd, G.W., Byfield, P.G.H. \& Foster, G.V. (1969) A radioimmunoassay for calcitonin M. Lancet, ii, 74.

Cunliffe, W.J., BlaCK, M.M., Hall, R., Johnstone, I.D.A., Hodgson, P., Shuster, S., GudmundsSon, T.V., Joplin, G.F., Williams, E.D., Woodhouse, N.J.Y., Galante, L. \& MACINTYRE, I. (1968) A calcitonin-secreting thyroid tumour. Lancet, ii, 63.

Da Strada, M. \& Zunchtes, G. (1976) Simultaneous radioenzymatic determination of plasma and tissue adrenaline, noradrenaline and dopamine within the fentamole range. Life Sciences, 19, 1161.

DefTos, L.J. (1974) Radioimmunoassay for calcitonin in medullary thyroid carcinoma. Journal of the American Medical Association, 227, 403.

Dymling, J.F., LJUNGBerg, O., Hillyard, C.J., Greenberg, P.B., Evans, I.M.A. \& MacInTYRe, I. (1976) Whisky: a new provocative test for calcitonin secretion. Acta endocrinologica, 82, 500.

EDITORIAL (1977) Sipple families. Lancet, i, 939.

Foster, G.V., Macintyre, I. \& Pearse, A.G.E. (1964) Calcitonin production and the mitochondrion-rich cells of the dog thyroid. Nature, 203, 1029. 
Galante, L.S., Gudmundsson, T.V., Matthews, E.W., TSE, A., WILliams, E.D., WoOdhouse, N.J.Y. \& MACINTYRE, I. (1968) Thymic and parathyroid origin of calcitonin in man. Lancet, ii, 537.

Hazard, J.B., Hawk, W.H. \& Crile, G. (1959) Medullary (solid) carcinoma of the thyroid - a clinicopathologic study. Journal of Clinical Endocrinology and Metabolism, 19, 152.

Hillyard, C.J., Greenberg, P.B., Coombes, R.C., MACINTYRe, I., LJUNGBerg, O. \& DYMLiNG, J.F. (1975) Applications of a radioimmunoassay for human calcitonin. In: Radioimmunoassay in Clinical Biochemistry (Ed by Pasternak, C.A.), pp. 245-252. Heyden \& Son Ltd, London.

LJUNGBERG, O. (1972) On medullary carcinoma of the thyroid. Acta pathologica et microbiologica scandinavica, Section A (suppl.), 231.

PearSe, A.G.E. (1966) The cytochemistry of the thyroid C cells and their relationship to calcitonin. Proceedings of the Royal Society, series B, 164, 478.

SAROSI, E. \& DoE, R.P. (1968) Familial occurrence of parathyroid adenomas, pheochromocytoma and medullary carcinoma of the thyroid with amyloid stroma (Sipple's syndrome). Annals of Internal Medicine, 68, 1305.
Schimke, R.N. \& HartmanN, W.H. (1965) Familial amyloidproducing medullary carcinoma and pheochromocytoma. Annals of Internal Medicine, 63, 1027.

SiPPLE, J.H. (1961) The association of pheochromocytoma with carcinoma of the thyroid gland. American Journal of Medicine, 31, 163.

Steiner, A.L., Goodman, A.D. \& Powers, S.R. (1968) Study of a kindred with pheochromocytoma, medullary thyroid carcinoma, hyperparathyroidism and Cushing's disease: $\frac{\mathcal{S}}{}$ multiple endocrine neoplasia type II. Medicine, 47, 371 .

SteVenson, J.C. \& HillyaRd, C.J. (1980) Tumour markers. In: Recent Results in Cancer Research, vol. 73, Thyroides Cancer (Ed by Duncan, W.), pp. 60-67 Springer-Verlag, $\vec{\circ}$ Heidelberg (in press)

TAYLOR, S. (1977) Bradshaw Lecture: Thyroid medullary carcinoma. Annals of the Royal College of Surgeons of England, 59, 374.

Wells, S.A., Ontiges, D.A., Cooper, C.W., Hennessy, J.F., Ellis, G.J., McPherson, H.T. \& SABiston, D.C. (1975) The early diagnosis of medullary carcinoma of the thyroid ir gland in patients with multiple endocrine neoplasia type II.. Annals of Surgery, 182, 362.

WILliams, E.D. (1966) Histogenesis of medullary carcinoma of the thyroid. Journal of Clinical Pathology, 19, 114. 